\title{
The effect of thermal annealing in a hydrogen atmosphere on tungsten deposited on 6H-SiC
}

\author{
Thabethe T. T. ${ }^{a^{*}}$, Hlatshwayo T. T., Njoroge E. G. ${ }^{a}$, Nyawo T. G. ${ }^{\text {a }}$ and Malherbe J. B ${ }^{a}$ \\ ${ }^{(a)}$ Department of Physics, University of Pretoria, Pretoria, 0002, South Africa \\ ${ }^{(b)}$ Department of Physics, University of Zululand, Kwa Dlangezwa, 3886, South Africa
}

\section{Abstract}

Tungsten (W) film was deposited on bulk single crystalline $6 \mathrm{H}-\mathrm{SiC}$ substrate and annealed in $\mathrm{H}_{2}$ ambient at temperatures of $700{ }^{\circ} \mathrm{C}, 800{ }^{\circ} \mathrm{C}$ and $1000{ }^{\circ} \mathrm{C}$ for 1 hour. The resulting solidstate reactions, phase composition and surface morphology were investigated by Rutherford backscattering spectrometry (RBS), grazing incidence X-ray diffraction (GIXRD) and scanning electron microscopy (SEM) analysis techniques. These results are compared with the vacuum annealed results reported in our earlier work. As-deposited RBS results indicated the presence of $\mathrm{W}$ and $\mathrm{O}_{2}$ in the deposited thin film, the GIXRD showed the presence of $\mathrm{W}$, $\mathrm{WO}_{3}, \mathrm{~W}_{5} \mathrm{Si}_{3}$ and WC. RBS results indicated the interaction between $\mathrm{W}$ and $\mathrm{SiC}$ was accompanied by the removal of oxygen at $700{ }^{\circ} \mathrm{C}$. The GIXRD analysis indicated the presence of $\mathrm{W}_{5} \mathrm{Si}_{3}$ and $\mathrm{WC}$ in the samples annealed at $700{ }^{\circ} \mathrm{C}$. At temperatures of $800{ }^{\circ} \mathrm{C}$ and $1000{ }^{\circ} \mathrm{C}, \mathrm{W}$ annealed in a $\mathrm{H}_{2}$ ambient further reacted with the $\mathrm{SiC}$ substrate and formed mixed layer containing silicide phases and carbide phases, i.e. $\mathrm{W}_{5} \mathrm{Si}_{3}, \mathrm{WSi}_{2}, \mathrm{WC}$ and $\mathrm{W}_{2} \mathrm{C}$. The SEM micrographs of the as-deposited samples indicated the $\mathrm{W}$ thin film had a uniform surface with small grains. Annealing at $800{ }^{\circ} \mathrm{C}$ led to the agglomeration of $\mathrm{W}$ grains into clusters making the surface rough.

Keywords: tungsten, $\mathrm{SiC}$, interface, reactions, annealing

Corresponding author: Thabsile Thabethe, Tel: 012420 4510,

email:Thabsile.Thabethe@up.ac.za 


\section{Introduction}

Silicon carbide ( $\mathrm{SiC}$ ) is used in high temperature gas cooled reactors (HTGRs), electronic devices, fusion reactors etc. [1-3]. This is due to its high thermal stability, high thermal conductivity, electric field strength, resistance against aggressive chemicals and abrasion [3-5]. In HTGRs, SiC is used for fuel kernel encapsulation in tri-structural isotropic (TRISO) particles. In these TRISO particles, $\mathrm{SiC}$ is the main diffusion barrier for radioactive fission products (FPs) [6], [7]. Failure of the TRISO particle in retaining FPs will lead to the release of the FPs into the primary cooling circuit thus causing danger of contamination to personnel and environment. There are several factors which may contribute to the failure of the $\mathrm{SiC}$ in retaining radioactive FPs. These include; thinning of the $\mathrm{SiC}$ layer due to reactions with FPs such as palladium $(\mathrm{Pa})$ and zirconium $(\mathrm{Zr})$ and the gas build up leading to a rise in pressure that may exerts strong tensile stress in the $\mathrm{SiC}$ and lead to cracks through which the FPs can escape [7-11].

These $\mathrm{SiC}$ drawbacks may be improved by enhancing its physical, mechanical, thermal and chemical properties. This can be achieved by adding a coating layer on the $\mathrm{SiC}$ layer of the TRISO particle [12], [13]. The use of tungsten (W) as a suggested coating material has good advantages such as a low sputtering yield, inherent heat resistance, high thermal conductivity, excellent corrosion and abrasion resistance [3]. The enhancement of the shielding effect of $\mathrm{SiC}$ will play a remarkable role in terms of improving the $\mathrm{SiC}$ layer strength. This may allow for higher burn-up and enrichment without causing harm to the structural integrity of the TRISO particle.

Recently, we reported on the vacuum annealing of a thin tungsten layer deposited on $6 \mathrm{H}-\mathrm{SiC}$ [14]. In this study, we report on the effect of thermal annealing of the same system in hydrogen and the reactions which occur due to annealing. The effect of heat treatment of W$\mathrm{SiC}$ structure in $\mathrm{H}_{2}$ is an important aspect which has not been studied in detail by other researchers.

\section{Experimental Procedure}

Semi-insulating $6 \mathrm{H}-\mathrm{SiC}$ single-crystal wafer of 2 inch diameter, $330 \mu \mathrm{m}$ thickness, with a micro pipe density of $<10 \mathrm{~cm}^{-2}$ and root mean square (rms) surface roughness of $<0.5 \mathrm{~nm}$ was used as starting material. The W sputtering target (99.9\% pure) was obtained from AJA 
International Inc. Thin $\mathrm{W}$ film was sputter-deposited on the $6 \mathrm{H}-\mathrm{SiC}$ wafer by initially mounting the wafer on a rotating sample holder to ensure that a uniform layer was deposited. The base pressure in the chamber was first pumped down to $10^{-7}$ Torr and then subsequently filled with Argon (Ar) gas to a pressure of $10^{-3}$ Torr. The Ar gas flow was kept constant at 8.0 SCCM. W target was sputter-cleaned for 10 minutes using Ar plasma before the actual sputtering process was done at room temperature. A thin-film layer of $\mathrm{W}$ was successfully deposited on the $\mathrm{SiC}$ substrate and the samples were subsequently annealed in hydrogen $\left(\mathrm{H}_{2}\right)$ gas of $99.95 \%$ purity at $700{ }^{\circ} \mathrm{C}, 800{ }^{\circ} \mathrm{C}$ and $1000{ }^{\circ} \mathrm{C}$ for 1 hour in a quartz tube furnace. The flow rate of $\mathrm{H}_{2}$ gas in the quartz tube was maintained at 250 SCCM.

All the samples were analysed using Rutherford backscattering spectrometry (RBS) before and after annealing. Simulation of RBS spectra was done using the RUMP code [15] to obtain the thickness of the $\mathrm{W}$ deposited layer, composition of deposited layer and the reaction zone. The energy used for the $\mathrm{He}^{+}$ions was $1.6 \mathrm{MeV}$ with a scattering angle of $165^{\circ}$. XRD analysis was performed using a Bruker D8 Discover XRD system with a $\mathrm{Cu} \mathrm{K}_{\alpha}$ radiation source to identify the phases present and orientation before and after heat treatment of the samples. The as-deposited sample was used to determine the angle of incidence with respect to the surface of the X-ray beam. Since the peaks of the single crystalline SiC substrate would much larger than the reaction product peaks and would dwarf them, the angle was reduced from $10^{\circ}$ to the point where the $\mathrm{SiC}$ peaks just disappeared. The final angle used for analysis was $0.5^{\circ}$. A field emission gun scanning electron microscopy (FEG-SEM) powered with a Zeiss Ultra 55 high resolution field emission microscope was used to study the surface morphology of the samples before and after annealing at the different temperatures.

\section{Results and discussion}

\subsection{Rutherford Backscattering Spectrometry (RBS)}

The RBS spectrum of $\mathrm{W}$ deposited on $6 \mathrm{H}-\mathrm{SiC}$ is shown in Fig. 1 and the corresponding simulated spectrum obtained by RUMP computer code is also included. The surface channel positions of the elements in Fig. 1 are indicated by the arrows. The thickness of the deposited W layer obtained from RUMP simulations was found to be $65 \mathrm{~nm}$, which was composed of 65.6 at. $\% \mathrm{~W}$ and 34.4 at.\% $\mathrm{O}_{2}$. This indicates that an oxide layer had form; $\mathrm{W}$ reacted with $\mathrm{O}_{2}$ to form tungsten oxide. 


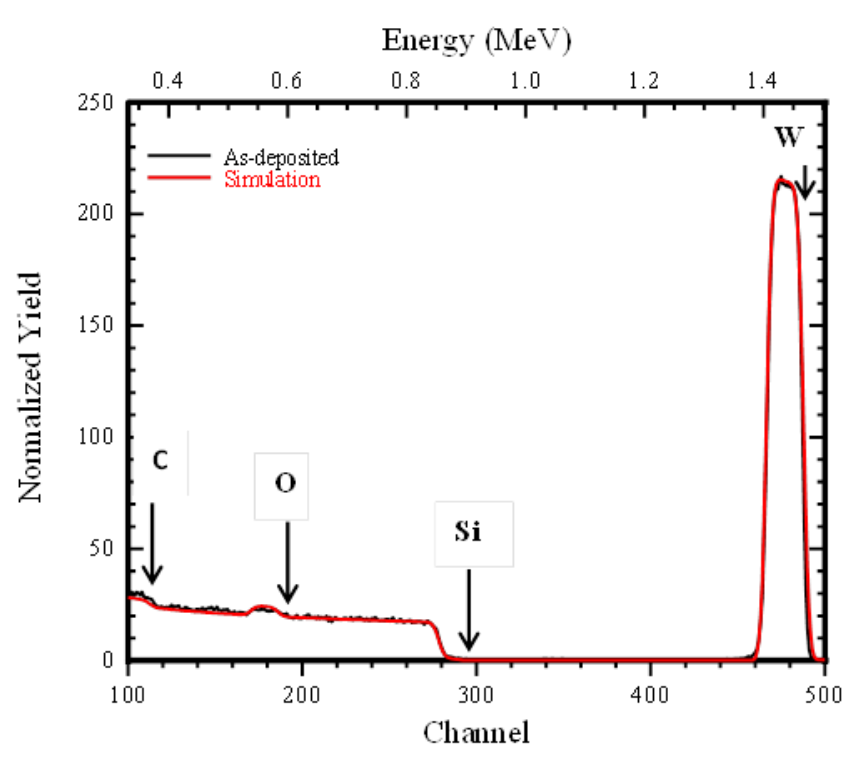

Fig 1: As-deposited RBS spectrum with the corresponding RUMP simulation.

The $\mathrm{W}$ thin film deposited in $6 \mathrm{H}-\mathrm{SiC}$ was annealed in $\mathrm{H}_{2}$ ambient for 1 hour at temperatures of $700{ }^{\circ} \mathrm{C}, 800^{\circ} \mathrm{C}$ and $1000^{\circ} \mathrm{C}$, and the corresponding RBS spectra are shown in Fig. 2. The as-deposited RBS profile has an oxygen peak at channel number 190 while the $700{ }^{\circ} \mathrm{C}$ annealed spectrum has no oxygen peak.

The as-deposited $\mathrm{W}$ peak has a lower peak height compared to the $700{ }^{\circ} \mathrm{C} \mathrm{W}$ peak. The difference between the two spectra can be explained to be due to the presence of oxygen in the as-deposited layer. The presence of oxygen in $\mathrm{W}$ reduced the peak height of the RBS spectrum of as-deposited sample. After the oxygen content had been reduced in the $\mathrm{W}$ film, the height of $\mathrm{W}$ peak increased as seen in Fig. 2. The increase in $\mathrm{W}$ peak height after annealing in hydrogen due to the removal of oxygen, has also been observed by other researchers [16], [17]. The RUMP simulation of the sample annealed at $700{ }^{\circ} \mathrm{C}$ indicated that a reaction had taken place between $\mathrm{W}$ and $\mathrm{SiC}$. This resulted in a $\mathrm{W}$ layer of $27 \mathrm{~nm}$, with a reaction zone (RZ) layer of $14 \mathrm{~nm}$ where the reaction between $\mathrm{W}$ and $\mathrm{SiC}$ had occurred as a result of the interdiffusion between $\mathrm{W}, \mathrm{Si}$ and $\mathrm{C}$. The composition of the RZ was obtained using RUMP simulation. The RBS spectrum was simulated with two layers in the RZ in order to have a good fit. The RUMP simulations of the initial layer suggests the presence of $\mathrm{W}$ and WC phases with concentrations of about $96.0 \%$ and $4.0 \%$ respectively. In the second layer, the $\mathrm{W}$ concentration was found to be $76.5 \%$, WC is $6.4 \%$ and $\mathrm{W}_{5} \mathrm{Si}_{3}$ concentration was 17.1 $\%$. 
There are two possible explanations for removal of oxygen in the deposited film: first one is, during annealing hydrogen reacts with $\mathrm{O}$ to form $\mathrm{H}_{2} \mathrm{O}$ according to chemical reactions in equation (1), (2) and (3) [18]:

$4 \mathrm{WO}_{3}+\mathrm{H}_{2} \leftrightarrow \mathrm{W}_{4} \mathrm{O}_{11}+\mathrm{H}_{2} \mathrm{O}$

$\mathrm{W}_{4} \mathrm{O}_{11}+3 \mathrm{H}_{2} \leftrightarrow 4 \mathrm{WO}_{2}+3 \mathrm{H}_{2} \mathrm{O}$

$\mathrm{WO}_{2}+2 \mathrm{H}_{2} \leftrightarrow \mathrm{W}+2 \mathrm{H}_{2} \mathrm{O}$

The second explanation is that carbon from the $\mathrm{SiC}$ reacted with oxygen to form carbon dioxide gas which then flowed out of the system together with the $\mathrm{H}_{2}$ gas [16]. The more plausible explanation in our case is the latter, i.e. that the $\mathrm{H}_{2}$ gas reacted with oxygen, leaving a pure $\mathrm{W}$ layer. To further investigate whether $\mathrm{H}_{2}$ reacts with $\mathrm{O}$ to form a pure $\mathrm{W}$ layer, as speculated above, the W-SiC samples were annealed at $600{ }^{\circ} \mathrm{C}$ (no interaction was expected at this temperature [19]) for 1 hour. The RBS spectrum and RUMP simulation (not shown here) indicated the presence of $\mathrm{W}$ with thickness of $30 \mathrm{~nm}$ with no oxygen. The loss of $\mathrm{W}$ might have been due to delamination. This thickness is of the same order of magnitude as the one obtained after annealing at $700{ }^{\circ} \mathrm{C}$ where some $\mathrm{W}$ delaminated. No interactions between $\mathrm{W}$ and SiC were detected. The RUMP simulations indicate that after annealing at $700{ }^{\circ} \mathrm{C}$, the carbon and silicon concentration in the RZ was almost stoichiometric. This result supports the theory that $\mathrm{H}_{2}$ reacts with oxygen in the deposited thin film.

A decrease in the height of the tungsten peak after annealing at $800{ }^{\circ} \mathrm{C}$ was observed indicating further reactions between the $\mathrm{W}$ and $\mathrm{SiC}$ took place, see Fig. 2. RUMP simulations indicated the presence of $\mathrm{C}$ in the $\mathrm{W}$ layer. $\mathrm{C}$ migrated to the $\mathrm{W}$ layer, were it reacted with $\mathrm{W}$ to form carbide(s) in the $\mathrm{W}$ matrix. Due to this diffusion of $\mathrm{C}$ into the $\mathrm{W}$ layer the amount of $\mathrm{Si}$ present in the $\mathrm{RZ}$ nearer to the $\mathrm{SiC}$ substrate was higher than that of $\mathrm{C}$. The $\mathrm{RZ}$ layer increased to $19 \mathrm{~nm}$ and the $\mathrm{W}$ layer containing the diffused $\mathrm{C}$ increased to $28 \mathrm{~nm}$. The RUMP simulation indicated the presence of tungsten silicide(s) and carbide(s). The reaction of tungsten with $\mathrm{SiC}$ resulting in the formation of silicides and carbides at temperatures of $700{ }^{\circ} \mathrm{C}$ and above has also been observed by other authors [5], [19], [20]. After annealing at $800{ }^{\circ} \mathrm{C}$ the RUMP simulation suggested the formation of two layers in the RZ similar to $700{ }^{\circ} \mathrm{C}$, from which the concentrations of present phases in each layer were determined. At $800{ }^{\circ} \mathrm{C}$, the first layer was composed of $92.4 \%$ of $\mathrm{W}$ and $7.6 \%$ of WC. While the second 
layer had a concentration of $62.8 \%$ of $\mathrm{W}, 17.4 \%$ of $\mathrm{W}_{2} \mathrm{C}, 14.4 \%$ of $\mathrm{W}_{5} \mathrm{Si}_{3}$ and $5.4 \%$ of $\mathrm{WSi}_{2}$.

Annealing at $1000{ }^{\circ} \mathrm{C}$ caused a further decrease of the $\mathrm{W}$ peak height/yield and a further shift of the $\mathrm{W}$ peak to the lower energy channels; see Fig. 2. An increase in C content in the W layer, that is, the first layer from RUMP simulation was observed to occur. This first layer was composed of W with $58.8 \%$ and $\mathrm{C}$ with $23.5 \%$ and the thickness of this layer increased to $38 \mathrm{~nm}$. From the RBS spectrum it can be observed that the presence of oxygen and $\mathrm{Si}$ at the surface of the W-SiC sample annealed at this temperature. The Si layer observed on the surface most probably came from the Si sample holder used during annealing at $1000{ }^{\circ} \mathrm{C}$. At this temperature $\mathrm{Si}$ sublimation was taking place with deposition of the $\mathrm{Si}$ on the W-SiC system. When the sample was taken out of the annealing chamber, exposure to air led to the oxidation of the Si layer. The RUMP simulations indicated that the surface of the samples had a thin layer composed of $\mathrm{Si}$ and $\mathrm{O}_{2}$. The reaction zone obtained from the RUMP simulation at $1000{ }^{\circ} \mathrm{C}$ was also composed of two layers with different concentrations of carbides and silicides in the different layers. Layer one had $\mathrm{W}, \mathrm{WC}$, and $\mathrm{WSi}_{2}$ concentrations of $26.45 \%, 47.0 \%$ and $26.55 \%$ respectively. The second layer had concentrations of 10.66 $\% \mathrm{~W}, 66.9 \% \mathrm{~W}_{2} \mathrm{C}, 16.32 \% \mathrm{~W}_{5} \mathrm{Si}_{3}$ and $6.12 \% \mathrm{WSi}_{2}$. The concentrations of the silicide phases $\left(\mathrm{WSi}_{2}\right.$ and $\left.\mathrm{W}_{5} \mathrm{Si}_{3}\right)$ in both layers increased with the increase in annealing temperature. The concentrations of the carbides formed ( $\mathrm{WC}$ and $\mathrm{W}_{2} \mathrm{C}$ ) varied with increase in temperature.

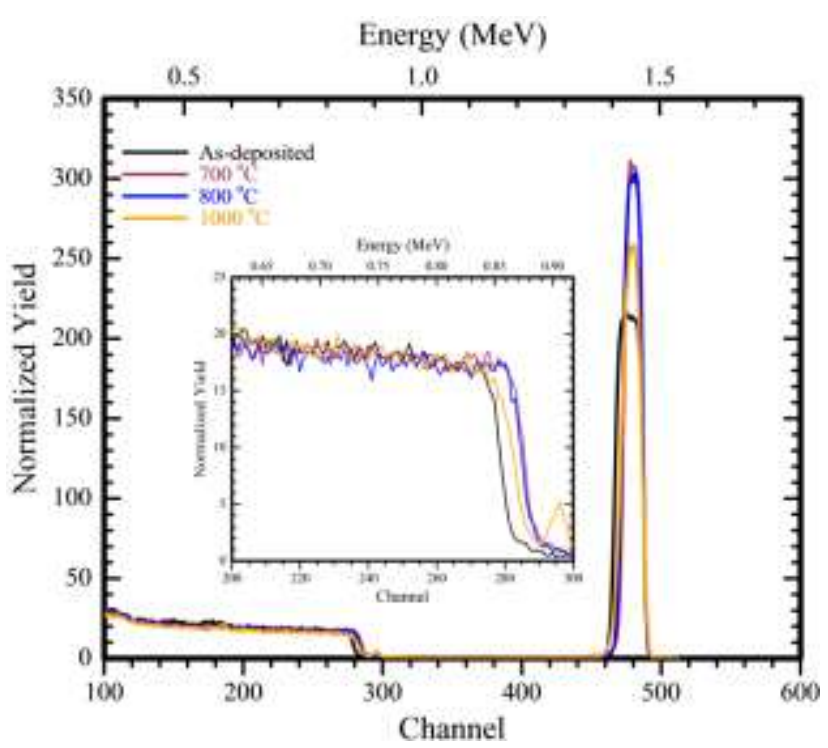

Fig. 2: RBS spectra of the as-deposited and annealed samples in $\mathrm{H}_{2}$ gas for 1 hour at temperatures of 700 to $1000^{\circ} \mathrm{C}$. 


\section{Grazing Incidence X-ray diffraction (GIXRD) results}

After RBS analysis, the same samples were examined using XRD at grazing incidence geometry to confirm the RBS results. GIXRD patterns of the W thin film deposited on $6 \mathrm{H}-$ $\mathrm{SiC}$ before and after annealing are depicted in Fig. 3. The as-deposited pattern had W peaks at $39.89^{\circ}, 43.91^{\circ}$ and $82.15^{\circ} 2 \theta$ positions attributed to (222), (211) and (222) planes respectively, $\mathrm{W}_{5} \mathrm{Si}_{3}$ peaks assigned to (310) and (512) planes at $29.49^{\circ}$ and $61.57^{\circ}$ were observed to be present. This implies that $\mathrm{W}$ reacted with $\mathrm{SiC}$ during deposition resulting in the formation of silicide and carbide. The carbide formed was WC corresponding to (101) and (100) at $2 \theta$ position $35.65^{\circ}$ and $48.38^{\circ}$ respectively. The appearance of $\mathrm{WO}_{3}(112)$ at the $34.26^{\circ} 2 \theta$ position and $\mathrm{WO}_{3}(111)$ at the $41.87^{\circ} 2 \theta$ position indicates the presence of an oxide in the as-deposited $\mathrm{W}$ film. The latter GIXRD result for as-deposited sample correlates with the RBS results discussed earlier in terms of the presence of oxygen in the W layer.

Annealing the $\mathrm{W}-\mathrm{SiC}$ samples at $700{ }^{\circ} \mathrm{C}$ resulted in an increase in the $\mathrm{W}$ peak intensities and additional $\mathrm{W}$ peaks appeared. The additional $\mathrm{W}$ peaks were due to the removal/reduction of $\mathrm{WO}_{3}$ at $2 \theta$ position $35.65^{\circ}$ by the hydrogen gas to form a $\mathrm{W}$ pure layer. This correlates with the RBS results after annealing the samples where the W peak height increased indicating the removal of oxygen present in the as-deposited $\mathrm{W}$ film. The increase in peak intensity of $\mathrm{W}$ from the broad peaks on as-deposited sample to the narrow peaks after annealing is due to the change in the polycrystalline nature of our samples to larger crystallites. An increase in the peak intensities of the $\mathrm{W}_{5} \mathrm{Si}_{3}$ and $\mathrm{WC}$ phases was observed to occur and was most likely due to further reactions between $\mathrm{W}$ and $\mathrm{SiC}$ taking place resulting in the increase in the volume fraction of these phases in the RZ.

Annealing at $800{ }^{\circ} \mathrm{C}$ resulted in the decrease of the $\mathrm{W}$-rich $\mathrm{W}_{5} \mathrm{Si}_{3}$ peak intensity and the formation of Si-rich $\mathrm{WSi}_{2}(224), \mathrm{WSi}_{2}(200)$ phases and $\mathrm{W}_{2} \mathrm{C}(610)$ at the $2 \theta$ positions $103.31^{\circ}, 45.22^{\circ}$ and $102.96^{\circ}$ respectively. This implies that a fraction of the $\mathrm{W}_{5} \mathrm{Si}_{3}$ phase reacted with $\mathrm{C}$ from $\mathrm{SiC}$ to form $\mathrm{WSi}_{2}$ and $\mathrm{W}_{2} \mathrm{C}$ thus resulting in a decrease in $\mathrm{W}_{5} \mathrm{Si}_{3}$ peak intensity. The possible reactions are represented by equations (4) and (5) below:

$18 \mathrm{~W}+15 \mathrm{SiC} \rightarrow 8 \mathrm{WC}+5 \mathrm{~W}_{5} \mathrm{Si}_{3}+7 \mathrm{C}$

$4 \mathrm{~W}_{5} \mathrm{Si}_{3}+7 \mathrm{C} \rightarrow 6 \mathrm{WSi}_{2}+7 \mathrm{~W}_{2} \mathrm{C}$

WC $\left(35.65^{\circ}\right)$ peak intensity increased after annealing at $800{ }^{\circ} \mathrm{C}$ (See Fig. 3.) compared to the $700{ }^{\circ} \mathrm{C}$ annealing. The increase in the peak intensity at $800{ }^{\circ} \mathrm{C}$ is due to the increase in the 
quantity of $\mathrm{WC}$ after further reaction between $\mathrm{W}$ and $\mathrm{SiC}$ and change in texture of the nature of our sample due to heat treatment.

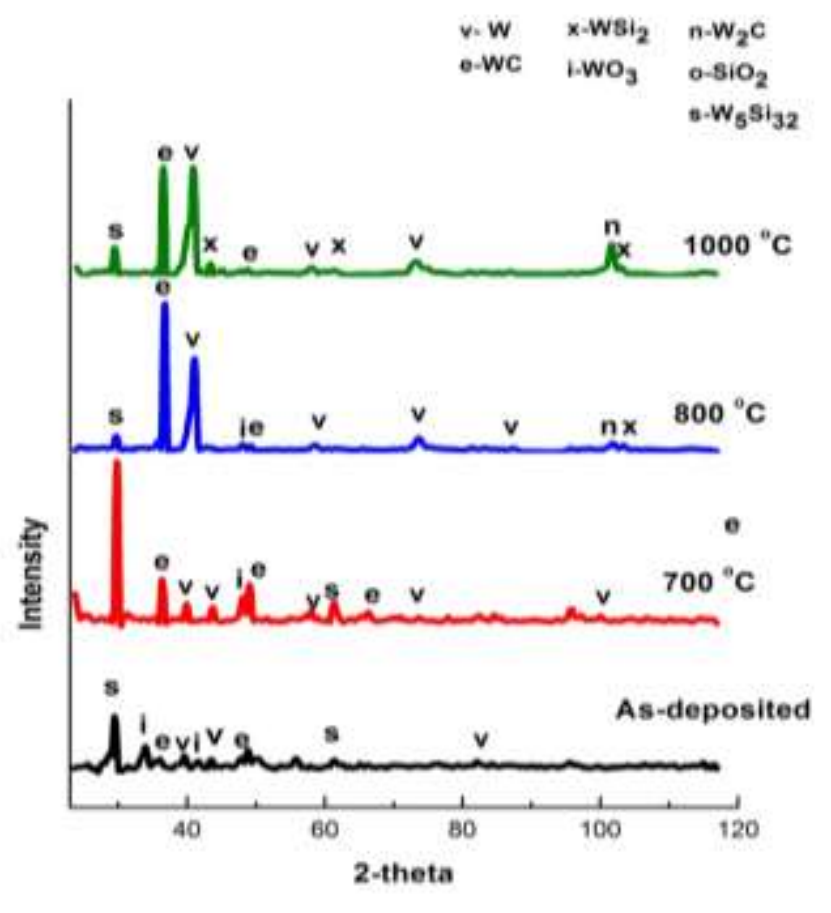

Fig. 3: Grazing incidence $\mathrm{X}$-ray diffraction patterns for $\mathrm{W}$-SiC after annealing in $\mathrm{H}_{2}$ at $700{ }^{\circ} \mathrm{C}, 800{ }^{\circ} \mathrm{C}$ and $1000{ }^{\circ} \mathrm{C}$.

Annealing at $1000{ }^{\circ} \mathrm{C}$ resulted in an increase in the intensity of the $\mathrm{W}_{2} \mathrm{C}$ peak $(2 \theta$ position $102.96^{\circ}$ ) compared to the annealing at $800{ }^{\circ} \mathrm{C}$. Additional peaks of $\mathrm{WSi}_{2}$ at $42.89^{\circ}$ and $62.3^{\circ}$ is observed to appear indicating further reactions at the RZ. The W peaks were still present after annealing at $1000{ }^{\circ} \mathrm{C}$ indicating that $\mathrm{W}$ layer had not fully reacted. WC (100) peak at position $48.38^{\circ}$ increased in intensity after annealing of the sample at $700{ }^{\circ} \mathrm{C}$ as a result of increase in the volume fraction of WC formed at this temperature. The annealing steps from $700{ }^{\circ} \mathrm{C}$ to $800^{\circ} \mathrm{C}$ and to $1000{ }^{\circ} \mathrm{C}$ resulted in a decrease in the peak intensity of WC (100) at $2 \theta$ position of $48.38^{\circ}$, this was due to transformation of this phase into WC (101). $\mathrm{W}_{2} \mathrm{C}$ peaks $\left(102.96^{\circ}\right)$ intensity increased due to the increase in $\mathrm{W}_{2} \mathrm{C}$ volume fraction. The WC peak height at $35.65^{\circ}$ increases when the samples were annealed at $700{ }^{\circ} \mathrm{C}, 800{ }^{\circ} \mathrm{C}$ and $1000{ }^{\circ} \mathrm{C}$ due to increase in the volume fraction and further reactions. 


\section{SEM Results}

Fig. 4 shows SEM micrographs of $\mathrm{W}$ deposited on $6 \mathrm{H}-\mathrm{SiC}$ before and after annealing at $700{ }^{\circ} \mathrm{C}, 800{ }^{\circ} \mathrm{C}$ and $1000{ }^{\circ} \mathrm{C}$ for 1 hour in $\mathrm{H}_{2}$ ambient. The SEM micrograph of the asdeposited sample in Fig. 4 (a), shows a fairly uniform surface of the $\mathrm{W}$ thin film, with very small grains (almost of the same size) that are evenly distributed. Annealing of the W-SiC samples in $\mathrm{H}_{2}$ at $700{ }^{\circ} \mathrm{C}$ and $800{ }^{\circ} \mathrm{C}$ for 1 hour led to a marked increase in the size of the grains in line with the XRD results (change in the peak intensity). Consequently, the surface topography of the $\mathrm{W}-\mathrm{SiC}$ annealed in $\mathrm{H}_{2}$ at $800{ }^{\circ} \mathrm{C}$ became rougher compared to the $700{ }^{\circ} \mathrm{C}$ annealed sample, see Fig. 4 (b \& c). Annealing at $1000{ }^{\circ} \mathrm{C}$ resulted in the formation of hillocks and a much rougher surface compared to the as-deposited. Also present were many small crystallites. The change in surface topography was due to recrystallization of $\mathrm{W}$ layer into larger grains and reactions taking place in the $\mathrm{W}-\mathrm{SiC}$ samples. The SEM results indicate a change in the crystalline nature of the sample surface when annealed at different temperatures; this confirms the causes of the change in the peak intensities in the XRD results is due to change in texture.
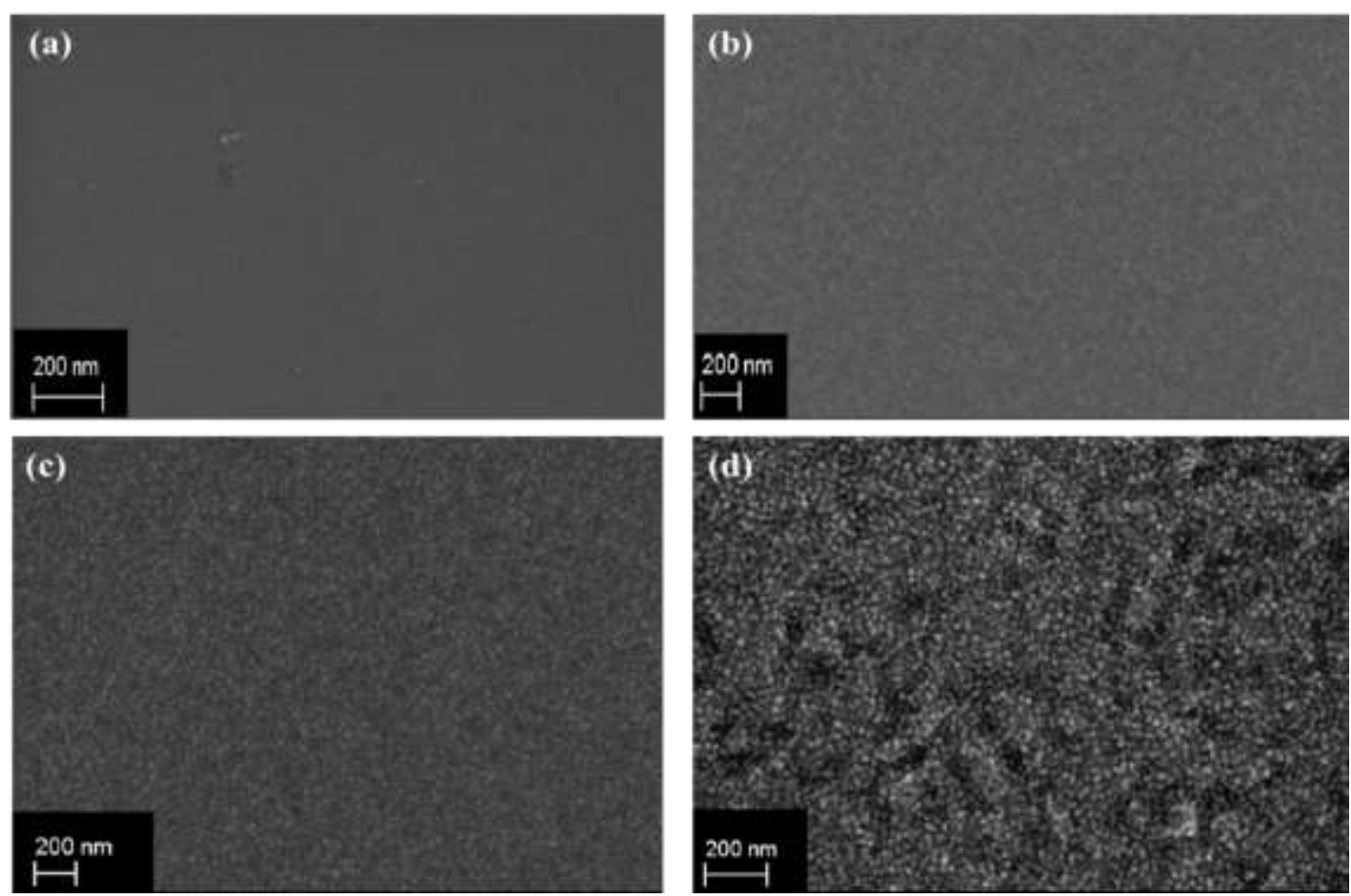

Fig 4: SEM micrographs of (a) As-deposited $\mathrm{W}$-SiC, (b) $700{ }^{\circ} \mathrm{C}$, (c) $800^{\circ} \mathrm{C}$ and (d) $1000^{\circ} \mathrm{C}$ for 1 hour annealed in Hydrogen 
The heat of formation for the phases in the W-Si-C system are reported in [21] and the most thermodynamically favoured initial phases to form are $\mathrm{WSi}_{2}$ and $\mathrm{WC}$. In this study, $\mathrm{W}_{5} \mathrm{Si}_{3}$ and WC were the initial phases observed to have formed at the $\mathrm{W}$-SiC interface of the asdeposited sample with the thermodynamically favoured $\mathrm{WSi}_{2}$ only appearing after higher annealing temperatures, i.e. at $800^{\circ} \mathrm{C}$ and above.

The reaction between $\mathrm{W}$ and $\mathrm{SiC}$ during deposition was also reported in earlier studies done by Geib et al.[20], in which they sputter deposited W on SiC. Their resulting Auger profiles for the as-deposited sample showed that a reaction between $\mathrm{W}$ and $\mathrm{SiC}$ took place to form $\mathrm{WSi}_{2}$ and WC. They explained the reaction to be induced by the damage on surface area of $\mathrm{SiC}$. The damage was caused by the cleaning of the substrate surface (in situ by ion milling), thereby weakening/breaking the bonds between SiC. Thus, lowering the amount of energy required to activate the reaction, leading to the reaction taking place during deposition.

In line with the explanation given by Geib et al.[20], the reaction between $\mathrm{W}$ and $\mathrm{SiC}$ on our as-deposited samples might be due to the Ar plasma cleaning before deposition. The presence of a silicide and a carbide on the as-deposited is due to the favourable kinetic and thermodynamic factors at the interface. It was observed from previous studies that the $\mathrm{W}$ films which were deposited on $\mathrm{SiC}$ resulted in the formation of $\mathrm{W}_{5} \mathrm{Si}_{3}$ as the initial silicide [24].

Rogowski et al. [5] reported that the reaction between a W thin film (400 nm) and 4H-SiC after annealing at $700{ }^{\circ} \mathrm{C}$ resulted in the formation of $\mathrm{W}_{5} \mathrm{Si}_{3}$ and $\mathrm{WSi}_{2}$ as the initial phases formed. While Baud et al. [19], found $\mathrm{W}_{5} \mathrm{Si}_{3}$ and $\mathrm{W}_{2} \mathrm{C}$ to be the initial phases formed in the reaction between $\mathrm{W}$ thin film $(500 \mathrm{~nm})$ and $\beta-\mathrm{SiC}(\mathrm{CVD})$ after annealing at $950{ }^{\circ} \mathrm{C}$. Goesmann et al. [22] [23], had $\mathrm{W}_{5} \mathrm{Si}_{3}$ and $\mathrm{WC}$ as their initial phases which formed as a result of $\mathrm{W}$ thin film $(150 \mathrm{~nm})$ reacting with $6 \mathrm{H}-\mathrm{SiC}$ after annealing at $1300^{\circ} \mathrm{C}$ and Geib et al. [20], found $\mathrm{WSi}_{2}$ and $\mathrm{WC}$ to be the initial phases present after RT deposition of $\mathrm{W}$ thin film (50 $\mathrm{nm}$ ) on SiC. In our results the initial phases formed were $\mathrm{W}_{5} \mathrm{Si}_{3}$ and $\mathrm{WC}$; also observed by other researchers as initial phases, as discussed before. The differences in the phases observed by different researchers are due to the difference in thickness of the $\mathrm{W}$ metal layer deposited, deposition method used and annealing temperature.

These $\mathrm{H}_{2}$ ambient results differ from our earlier work where $\mathrm{W}$ was deposited on SiC and annealed in vacuum at $700{ }^{\circ} \mathrm{C}$ to $1000{ }^{\circ} \mathrm{C}$ for 1 hour [14]. The RBS spectrum after annealing at $700{ }^{\circ} \mathrm{C}$ for the vacuum annealed samples had oxygen peak and did not show the changes 
(i.e. in peak height and width) as observed in the $\mathrm{H}_{2}$ annealed samples. The first RBS evidence of a reaction between $\mathrm{W}$ and $\mathrm{SiC}$ was only after vacuum annealing at $850{ }^{\circ} \mathrm{C}$. For $\mathrm{H}_{2}$ ambient annealing at $700{ }^{\circ} \mathrm{C}$ samples, no oxygen was detected and a reaction between the $\mathrm{W}$ and the SiC occurred. The GIXRD analysis for vacuum annealing resulted in the formation of carbides $\left(\mathrm{W}_{3} \mathrm{C}\right.$ and $\mathrm{WC}$ ) as the initial phases, while in the $\mathrm{H}_{2}$ ambient, $\mathrm{W}_{5} \mathrm{Si}_{3}$ and $\mathrm{WC}$ were the initial phases formed. The formation of $\mathrm{W}_{2} \mathrm{C}$ and $\mathrm{WSi}_{2}$ was observed to take place at $800{ }^{\circ} \mathrm{C}$ for $\mathrm{H}_{2}$ annealed samples, and for vacuum annealed samples it was observed at $900{ }^{\circ} \mathrm{C}, \mathrm{W}_{5} \mathrm{Si}_{3}$ was not present for the vacuum annealed samples. Annealing of the $\mathrm{W}$-SiC samples in vacuum at $800^{\circ} \mathrm{C}$ for 1 hour led to the agglomeration of the $\mathrm{W}$ grains into islands clusters causing hillocks. The formation of islands on the vacuum annealed samples at $800{ }^{\circ} \mathrm{C}$ might be due to presence of oxides in the vacuum annealed samples, which is relatively high as compared to the $\mathrm{H}_{2}$ annealed samples.

\section{Summary}

The interaction of a thin $\mathrm{W}$ film on $\mathrm{SiC}$ was investigated. The resulting solid-state reactions, phase composition and surface morphology were analysed using RBS, GIXRD and SEM. The samples were annealed in $\mathrm{H}_{2}$ ambient at $700{ }^{\circ} \mathrm{C}, 800{ }^{\circ} \mathrm{C}$ and $1000{ }^{\circ} \mathrm{C}$ for 1 hour. The GIXRD spectra of the as-deposited sample showed that reactions had taken place, with the presence of $\mathrm{W}_{5} \mathrm{Si}_{3}, \mathrm{WO}_{3}$ and $\mathrm{WC}$. The surface of the as-deposited samples analysed with SEM showed a fairly uniform $\mathrm{W}$ thin film, with tiny grains that were evenly distributed. Oxygen from the as-deposited sample was detected on RBS and this was present in the form of $\mathrm{WO}_{3}$ as observed from the XRD analysis.

The phases identified after annealing at $700{ }^{\circ} \mathrm{C}$ were $\mathrm{W}_{5} \mathrm{Si}_{3}$ and $\mathrm{WC}$. The XRD patterns for samples annealed in $\mathrm{H}_{2}$ ambient at temperatures of $800{ }^{\circ} \mathrm{C}$ and $1000{ }^{\circ} \mathrm{C}$ resulted in the formation of $\mathrm{WSi}_{2}$ and $\mathrm{W}_{2} \mathrm{C}$. Increase in temperature led to the increase in $\mathrm{W}$ grain size when annealing in $\mathrm{H}_{2}$ ambient. Annealing of the samples in $\mathrm{H}_{2}$ atmosphere assisted in the reduction/removal of oxygen and the temperature of reaction between $\mathrm{W}$ and $\mathrm{SiC}$ was lowered compared vacuum annealing. 


\section{Acknowledgement}

The authors wish to thank Mr T. Ntsoane from NECSA for his assistance with XRD analysis and Dr D.Y. Momodu for assisting with the annealing of the samples and analysis of the results. This work is based upon research supported by the National Research Foundation (NRF), South Africa. Any opinion, findings and conclusions or recommendations expressed in this work are those of the authors and the NRF do not accept any liability with regard thereto. T. T. Thabethe acknowledges the financial support from the NRF.

\section{References}

[1] V.B. Shields, Applications of Silicon Carbide for High Temperature Electronics and Sensors, NASA Jet Propulsion Laboratory, Tech Briefs 0145-319X, 1996.

[2] P. G. Neudeck, SiC Technology, The VLSI Handbook, The Electrical Engineering Handbook Series, CRC Press Inc., Boca Raton, 2007.

[3] S.J. Son, K.H. Park, Y. Katoh, A. Kohyama, J. Nucl. Mater. 329-333 (2004) 1549.

[4] K. Shimoda, N. Eiza, J. Park, T. Hinoki, A. Kohyama, S. Kondo, Mater. Trans. 47 (2006) 1204.

[5] J. Rogowski, A. Kubiak, Mater. Sci. Eng. B 191 (2015) 57.

[6] J.B. Malherbe, N.G. van der Berg, A.J. Botha, E. Friedland, T.T. Hlatshwayo, R.J. Kuhudzai, E. Wendler, W. Wesch, P. Chakraborty, E.F. da Silveira, Nucl. Instruments Methods Phys. Res. Sect. B-Beam Interact. with Mater. Atoms 315 (2013) 136.

[7] E. Friedland, N.G. van der Berg, J.B. Malherbe, J.J. Hancke, J. Barry, E. Wendler, W. Wesch, J. Nucl. Mater. 410 (2011) 24.

[8] E.G. Njoroge, C.C. Theron, J.B. Malherbe, O.M. Ndwandwe, Nucl. Instruments Methods Phys. Res. Sect. B Beam Interact. with Mater. Atoms 332 (2014) 138.

[9] K. Verfondern, H. Nabielek, J. M. Kendall, Nucl. Eng. Technol. 39 (2007) 603.

[10] D.A. Petti, J. Buongiorno, J.T. Maki, R.R. Hobbins, G.K. Miller, Nucl. Eng. Des. 222 
(2003) 281.

[11] T.M. Besmann, R.E. Stoller, G. Samolyuk, P.C. Schuck, S.I. Golubov, S.P. Rudin, J.M. Wills, J.D. Coe, B.D. Wirth, S. Kim, D.D. Morgan, I. Szlufarska, J. Nucl. Mater. 430 (2012) 181.

[12] T. Ganne, J. Crépin, S. Serror, A. Zaoui, Acta Mater. 50 (2002) 4149.

[13] Y. Gao, S. Zheng, K. Zhu, Mater. Lett. 50 (2001) 358.

[14] T.T. Thabethe, T.T. Hlatshwayo, E.G. Njoroge, T.G. Nyawo, T.P. Ntsoane, J.B. Malherbe, Nucl. Instruments Methods Phys. Res. Sect. B Beam Interact. with Mater. Atoms (2015).

[15] L.R. Doolittle, Nucl. Instruments Methods Phys. Res. Sect. B Beam Interact. with Mater. Atoms 9 (1985) 344.

[16] Y. Li, J.P. Li, C.C. Jia, X.Q. Liu, Int. J. Miner. Metall. Mater. 19 (2012) 1149.

[17] S. Xu, L. Diao, J. Vac. Sci. Technol. A Vacuum, Surfaces, Film. 26 (2008) 360.

[18] J. H. Hougen, R. R. Reeves, G. G. Mannella, Ind. Eng. Chem. 48 (1956) 318.

[19] L. Baud, C. Jaussaud, R. Madar, C. Bernard, S. Chen, Mater. Sci. Eng. B 29 (1995) 126.

[20] K.M. Geib, C. Wilson, R.G. Long, C.W. Wilmsen, J. Appl. Phys. 68 (1990) 2796.

[21] W.F. Seng, P.A. Barnes, Mater. Sci. Eng. B 72 (2000) 13.

[22] F. Goesmann, R. Schmid-Fetzer, Mater. Sci. Eng. B 46 (1997) 357.

[23] F. Goesmann, R. Schmid-Fetzer, Mater. Sci. Eng. B 34 (1995) 224. 